\title{
Training and experiences in ultrasound and focused echo among post graduate trainees in anaesthesia, critical care and emergency medicine
}

\author{
Dilshan Priyankara ${ }^{1 *}$, Sureswarasarma Jegatheepan ${ }^{2}$, Edirisooriya Maddumage Manoj ${ }^{1}$ \\ Consultant Intensivist ${ }^{1}$, Senior registrar in Anaesthesiology ${ }^{2}$, National Hospital of Sri Lanka, \\ Colombo, Sri Lanka
}

\begin{abstract}
Introduction: Use of ultrasound scans (USS) has rapidly expanded and it is being used by many nonradiology specialists in fields such as anaesthesia, critical care and emergency medicine. There are well established guidelines on the use of USS in these specialities. Training in USS should be appropriately supervised and should lead to an accreditation to ensure the quality and to minimize mistakes.

Study objectives: We evaluated the training, experience, and confidence in USS/Focused ECHO among anaesthesia, critical care and emergency medicine trainees.

Methods: An online survey was sent to the post-graduate trainees in anaesthesia, critical care and emergency medicine who wereundergoing local training in Sri Lanka during August-September 2017. No ethical approval was required, and participation was entirely voluntary with responses kept anonymised.

Results: Out of 69 responders, only $25(36.2 \%)$ had a dedicated training programme in USS/F-ECHO. Trainees gained their knowledge mainly from their seniors $(52.1 \%)$, workshops $(46.3 \%)$ and local educational supervisor (37.6\%). Only $9(13.1 \%)$ maintained a log book. Majority were always or often confident in performing vascular USS. However, trainees were least confident in F-ECHO.

Conclusions: There should be a dedicated USS and focused ECHO programme and a curriculum for the trainees in anaesthesia, critical care and emergency medicine and they should be encouraged to maintain a $\log$ book of their training experiences.
\end{abstract}

Keywords: Training in FICE; point of care ultrasound; critical care

\section{Introduction}

Over the last decade, there has been major advances in ultrasound (USS) technology. This has led to more interest and use of USS beyond radiology into various specialities such as critical care, anaesthesia and emergency medicine. Due to the development of technology and availability of portable, "point of care' machines, specialists could use ultrasound in their day to day clinical practice. USS has been used mainly for vascular access procedures in anaesthesia in the previous era.

However, the use of USS technology has gone beyond its use for vascular access to regional anaesthesia, various diagnostic and therapeutic procedures using thoracic USS (diagnosis and treatment of pleural effusions and pneumothoraces,

*Correspondence: Dilshan Priyankara

E mail:dilsh123@gmail.com

https://orcid.org/0000-0002-6739-0950

Received: 04/07/2018

Accepted:08/07/2018

DOI: http://doi.org/10.4038/slja.v26i2.8356

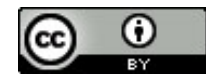

pulmonary oedema), abdominal scanning (Focused Assessment with Sonography in Trauma - FAST) in emergency medicine and focused transthoracic echocardiography in critical care (F-ECHO).

There are well established guidelines onthe use of USS in anaesthesia, critical are and in emergency medicine. ${ }^{1,2}$ These guidelines highlight the training syllabus and requirements for an ultra-sonographer to ensure competency in individual practice. Learning USS is a distinct process which should be appropriately supervised and should lead to an accreditation to ensure the quality and to minimizemistakes. ${ }^{3,4}$ Many practitioners and trainees in these fields are getting ad hoc training and have learned ultrasound techniques 'on the job'. There are several USS/ F-ECHO workshops in a given year conducted by clinical societies, colleges and various groups.

We intended to evaluate the training, experience, and confidence in undertaking USS/Focused ECHO among anaesthesia, critical care and emergency medicine post graduate trainees in Sri Lanka.

\section{Materials and Methods}

We constructed a questionnaire (20- questions) including multiple choice questions and yes/no answers. Using this questionnaire, we performed an online survey during August -September 2017 among 
the post-graduate trainees in anaesthesia, critical care and emergency medicine currently undergoing local training in Sri Lanka. The trainees who have completed both local and overseas training and working as acting consultants were not questioned. However, trainees who are doing local training after overseas training were included in the study. The link was sent using an online survey application. Responses were collected online during September 2017.The data were analysed using SPSS 22.0 statistical package. No regional or institutional ethics approval was required and participation was entirely voluntary with responses kept anonymous.

\section{Results}

The survey was circulated online to 98 trainees undergoing local training in Sri Lanka during the survey period of August 2017 to September 2017 and $71(72.4 \%)$ replied. Total of 69 responses were analysed due to incomplete data from 2 responders.

\section{General data}

Table 1 highlights the demographic data and stage of training. Out of 69 trainees, $49(71 \%)$ of the responders were trainees in anaesthesia and 41 $(59.6 \%)$ were undergoing their registrar training at the time of the survey.

Table 1: General data and demographics

\begin{tabular}{|l|l|}
\hline Characteristic & $\mathbf{n ~ ( \% )}$ \\
\hline Age & $34.67 \pm 3.05$ \\
\hline Current specialty & \\
\hline Anaesthesia & $49(71)$ \\
\hline Critical care Medicine & $14(20.3)$ \\
\hline Emergency Medicine & $6(8.7)$ \\
\hline Current level of training & \\
\hline Registrar & $41(59.4)$ \\
\hline Senior registrar without overseas training & $17(24.6)$ \\
\hline Senior registrar with overseas training & $11(15.9)$ \\
\hline
\end{tabular}

\section{Training programme}

Out of 69 responders, only $25(36.2 \%)$ have undergone a dedicated special training programme in USS/F-ECHO. Trainees who did not have a specific training programme, mainly gained their knowledge on USS/F-ECHO from their seniors (52.1\%), USS/FECHO workshops $(46.3 \%)$ and from the local educational supervisor (37.6\%).
Table 2: Training programme

\begin{tabular}{|l|l|l|}
\hline Question & \multicolumn{2}{|l|}{$\mathbf{n}(\mathbf{\%})$} \\
\hline $\begin{array}{l}\text { Have you had a dedicated special training } \\
\text { programme in USS/focused ECHO during } \\
\text { your speciality training? }\end{array}$ & Yes & No \\
\cline { 2 - 3 } & $\begin{array}{l}25 \\
(36.2)\end{array}$ & $\begin{array}{l}44 \\
(63.8)\end{array}$ \\
\hline $\begin{array}{l}\text { If you had followed a dedicated training } \\
\text { program for USS/Focused ECHO, how } \\
\text { long you had the training? }\end{array}$ & \\
\hline$<3$ months & \\
\hline $3-6$ months & $46(66.7)$ \\
\hline $7-12$ months & $22(31.9)$ \\
\hline In which category you had training? * & $1(1.4)$ \\
\hline Vascular USS & $19(27.5)$ \\
\hline Lung USS & $23(33.3)$ \\
\hline Abdominal USS & $20(28.9)$ \\
\hline F-ECHO & $23(33.3)$ \\
\hline Other & $6(8.6)$ \\
\hline $\begin{array}{l}\text { If you have not followed any dedicated } \\
\text { training programme in USS/ ECHO, from } \\
\text { where you have got experience in doing it? } \\
*\end{array}$ & \\
\hline Local educational supervisor & $26(37.6)$ \\
\hline Overseas educational supervisor & $4(5.7)$ \\
\hline USS/F-ECHO workshops & $32(46.3)$ \\
\hline Seniors & $36(52.1)$ \\
\hline Others & $4(5.7)$ \\
\hline
\end{tabular}

\section{*multiple options were allowed}

\section{Use of USS/ECHO}

The use of USS/F-ECHO is demonstrated in Table 3. In the survey, most $(62,89.8 \%)$ had access to an ultrasound scanner and $67(97.1 \%)$ performed USS/FECHO during their training. In total, $50(73.3 \%)$ of the trainees performed USS more than once a week. However, only $9(13.1 \%)$ maintained a log book in USS/F-ECHO. Majority were always or often confident in performing vascular USS. However, trainees were least confident in F-ECHO category (Fig 2).

Table 3: Use of USS/F-ECHO among the trainees

\begin{tabular}{|l|c|c|}
\hline Question & \multicolumn{2}{|c|}{$\mathbf{n}(\%)$} \\
\hline $\begin{array}{l}\text { Have you used ultrasound/ focused ECHO during } \\
\text { your speciality training? }\end{array}$ & Yes & No \\
\cline { 2 - 3 } & $67(97.1)$ & $2(2.9)$ \\
\hline $\begin{array}{l}\text { Do you have enough access to USS/ ECHO } \\
\text { scanners during local training? }\end{array}$ & $62(89.8)$ & $7(10.2)$ \\
\hline Do you maintain a USS/ECHO Log book? & $9(13.1)$ & 60 \\
& & $(86.9)$ \\
\hline $\begin{array}{l}\text { How frequently do you use USS/Focused ECHO } \\
\text { during your speciality training? }\end{array}$ & & \\
\hline \multicolumn{1}{|c|}{ Once a week } & $28(13(18.8)$ \\
\hline Two- three times a week & \multicolumn{2}{|c|}{$62(31.8)$} \\
\hline Four to five times a week & \multicolumn{2}{|c|}{} \\
\hline Once a month & & \\
\hline
\end{tabular}




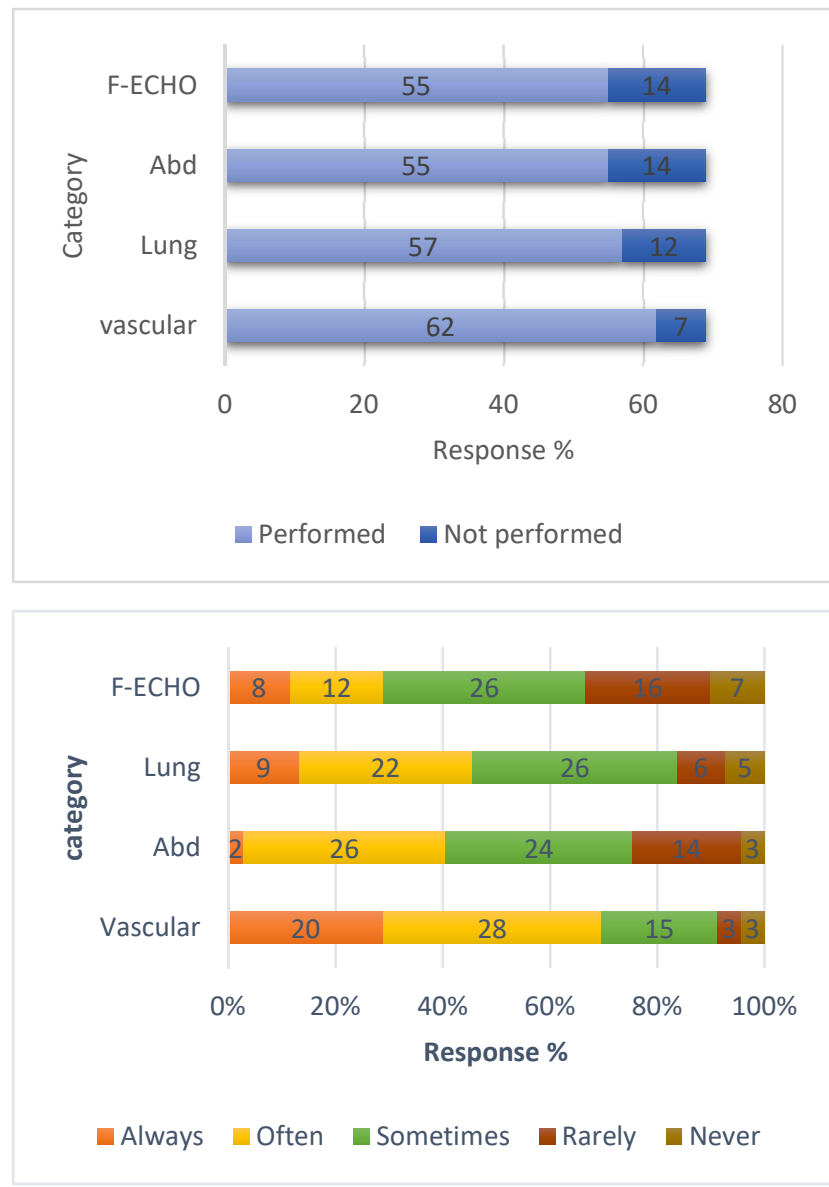

Figure 2: Confidence in performing USS/FECHO among trainees. $(n=69)$

Use of ultrasound has rapidly expanded beyond the boundaries of the radiologist and is being used by many other non-radiology specialists such as anaesthesia, critical care and emergency medicine. However, it should be used at appropriate situations and misinterpretation of findings should be avoided. Therefore, a formal training programme is essential for these non- radiology trainees. In our survey, majority of trainees admitted that they do not have a formal dedicated USS/ F-ECHO programme during their training period as a registrar or a senior registrar. Therefore, most of them relied on advice and supervision from their seniors and USS/F-ECHO workshops. A log book of scans performed could be used as an assessment tool of the trainee's ability to perform USS/F-ECHO. However, in our survey only $9(13.1 \%)$ maintained a log book. This reflects that there is no formal assessment of the trainees' competency of performing USS/F-ECHO.

A dedicated programme and allowing a dedicated time for USS/F-ECHO was a strong request from many trainees.
Results revealed that most trainees have quick access to an USS scanner and few suggested that an ECHO -probe was unavailable to perform F-ECHO. Thus, development of a structured training programme is much easier due to the availability of scanners. Majority of the trainees are confident in performing vascular USS. This could be due to the fact that majority of the responders were trainees in anaesthesia and the use of vascular USS is a routine practice during anaesthesia. However, majority were not confident in performing F-ECHO. This may be due to the lack of supervision and lack of specific training in these aspects.

\section{Conclusions and recommendations}

This survey illustrates that there should be a dedicated USS and focused ECHO programme and a curriculum specially for the trainees in anaesthesia, critical care and emergency medicine. We need to identify the trainers who can deliver a dedicated training for these trainees and lead them to achieve accreditation in USS and ECHO. Trainees should maintain a $\log$ book on USS/ECHO performed and should be reviewed with their mentors if available.

\section{References}

1. National Institute for Health and Clinical Excellence. Guidance on the use of ultrasound locating devices for placing central venous catheters.

https://www.nice.org.uk/guidance/ta 49 (accessed 25/10/2017).

2. Ultrasound in anaesthesia and intensive care: a guide to training,

https://www.aagbi.org/publications/guidelines/ultraso und-anaesthesia-and-intensive-care-guide-training. (accessed 25/10/2017).

3. Sites BD, Gallagher JD, Cravero J, Lundberg J, Bilke GT. The learning curve associated with a simulated ultrasound - guided interventional task by inexperienced anesthesia residents. Regional Anesthesia and Pain Medicine 2004; 29: 544-8.

https://doi.org/10.1097/00115550-200411000-00007 PMid: 15635513

4. Sites BD, Spence BC, Gallagher JD, Wiley CW, Bertrand ML, Bilke GT. Characterizing novice behaviour associated with learning ultrasound-guided peripheral regional anesthesia. Regional Anesthesia and Pain Medicine 2007; 32: 107-15.

https://doi.org/10.1097/00115550-200703000-00003 PMid: 17350520 